\title{
Morbilli Epidemic in Sarajevo Canton, Bosnia and Herzegovina 2019: A Review of Hospitalized Children with Measles at the Pediatric Clinic
}

\author{
Ganimeta Bakalović1*, Samir Bejić2 ${ }^{1 *}$ Sandra Joković ${ }^{3}$, Jovana Panic $^{1}$, Faruk Husremović ${ }^{4}$
}

${ }^{1}$ Department of Pulmonology, Pediatric Clinic of Clinical Center of University in Sarajevo, Sarajevo, Bosnia and Herzegovina; ${ }^{2}$ Health Care Center, Sarajevo, Bosnia and Herzegovina; ${ }^{3}$ University in East Sarajevo, Medical Faculty Foča, Foča, Bosnia and Herzegovina; ${ }^{4}$ Department of Urology, Cantonal Hospital, Zenica, Bosnia and Herzegovina

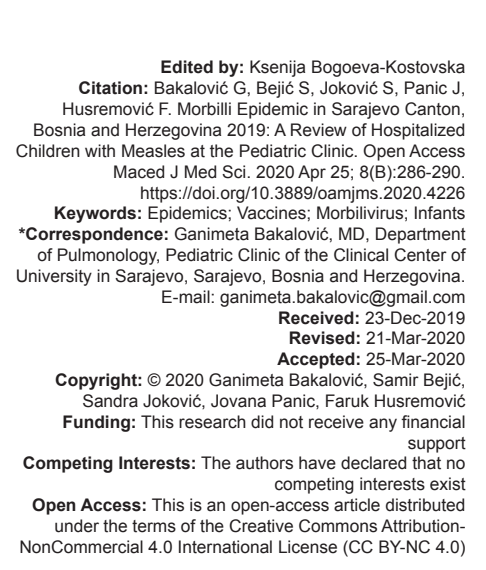

Introduction

\begin{abstract}
Measles is a highly contagious infectious disease caused by morbillivirus from the Paramyxoviridae family. The disease is met in endemoepidemic form most commonly in children of preschool and early school age. In our region, it shows the seasonal pattern of occurrence, with the peak incidence in autumn, winter, and spring. The virus is transmitted by a drop path from the nose, mouth, or throat of an infected person and can remain infectious in the air for up to $2 \mathrm{~h}$ [1]. There is an estimation of $1,00,000$ deaths worldwide annually, mainly among children under 5 years of age [2].
\end{abstract}

Measles is not a harmless disease. Before global vaccination, measles resulted in the death of 2 to 3 million people worldwide [3]. Once thought to have been eradicated, measles continues to be the leading cause of morbidity and mortality in the world, although the consequences of the disease can be prevented by vaccination [4].

\begin{abstract}
BACKGROUND: Measles is a highly contagious infectious disease caused by morbillivirus which usually affects young children. Once thought to have been eradicated, measles continues to be the leading cause of morbidity and

AIM: The purpose of this research is to analyze the risk factors and clinical characteristics of children hospitalized at patients into two groups: Infants and children over one year of age. We diagnosed measles clinically, or through the RESULTS: A total of 23 patients, aged 1 month to 14 years, were hospitalized at the Pediatric Clinic, accounting for $3.5 \%$ of the total number of the diseased children. The largest numbers of hospitalized patients were infants $9(39.1 \%)$. Comorbidities were present in 9 (39.1\%) subjects, and the most common complication was bronchopneumonia, far-reaching consequences of non-vaccination. Infants are critically endangered, as the most sensitive part of population, especially if the collective immunity is impaired.
\end{abstract} that, according to the World Health Organization (WHO), contributed to over 41,000 cases between January 2018 and June 2018. Of these 41,000 cases, 37 have resulted in death. The greatest factor that has contributed to this increase is a low vaccination rate compared to the previous years [5]. Some highly developed countries have been able to eradicate measles as a result of comprehensive vaccination and surveillance programs. In particular, certain parts of Europe, Central and South America, Asia, the Pacific, and Africa have been the most affected by measles. In these regions, a lack of vaccination is the greatest contributor to the development of the disease. In 2014 and 2015 , more than 5000 people became ill in the measles epidemic in Bosnia and Herzegovina. In only one Canton, Sarajevo Canton, out of the ten existing cantons in the Federation of Bosnia and Herzegovina, 840 patients were registered from the beginning of 2019 to June 28, 2019. The lack of vaccination is a major risk factor for the development of the disease. Other factors include immunosuppression, preterm 
infants, and the absence of maternal vaccination. Measles can cause life-threatening complications, and around $30 \%$ of patients experience multiple system and organ complications [6]. Measles infection causes immunosuppression and infected individuals are at risk of coinfection by respiratory and gastrointestinal viruses and secondary bacterial infections, most commonly with Staphylococcus aureus, Streptococcus pneumonia, and Haemophilus influenzae. Diarrhea is a complication that occurs with an incidence of $8 \%$. Otitis media is most common in small children. The incidence of encephalitis and acute disseminating encephalomyelitis is 1 in 1000 cases. Subacute sclerotising panencephalitis (SSPE) is a late-onset lethal degenerative disease of the CNS, occurring usually 7-10 years after the initial measles infection [7]. Pneumonia, which is also the most common cause of morbidity and mortality, can occur as the most common and most serious complication of this disease [8].

The aim of this research is to analyze the risk factors and clinical characteristics of children hospitalized at the Pediatric Clinic under the diagnosis of measles during morbilli epidemic in Sarajevo Canton 2019.

\section{Patients and Methods}

We retrospectively analyzed medical histories of patients hospitalized due to measles at the Pediatric Clinic of the Clinical Centre of University in Sarajevo from January to June 2019. We divided patients into two groups according to age. The first group consisted of infants and the second group of children older than one year of age. The average length of hospital stay was 12 days. We analyzed the socio-demographic characteristics, vaccine status, comorbidity, complications, and the outcome of the disease. Our patients had the following diseases as comorbidities: Steroid-resistant nephrotic syndrome, Otahara syndrome (early infantile epileptic encephalopathy), epilepsy, complex congenital heart defects, renal dysplasia, cerebral palsy, Rett syndrome, and surgery for esophageal atresia. Patients were diagnosed clinically, based on the specific clinical characteristics of the measles or by ELISA test for serum IgM for measles virus. The inclusion criteria were all hospitalized children aged $0-18$ years old, in whom we confirmed the diagnosis of measles. The exclusion criteria were all hospitalized children aged 0-18 years, who were suspected of measles, but we did not prove the disease. The results of the research are shown in the form of numbers and percentages. We have obtained permission from the Ethics Committee for data analysis.

\section{Results}

A total of 23 patients aged from 1 month to 14 years were hospitalized at the Pediatric Clinic which represented $3.58 \%(23 / 642)$ of the total number of patients in the Sarajevo Canton, who were under pediatric care. Others who required hospitalization, but were not complicated cases, were hospitalized at the clinic for infectious diseases at the Clinical Center of University in Sarajevo, and their data were not available. According to the official data from the Institute for Public Health of the Sarajevo Canton, between January and June 2019, a total of 840 cases of measles were recorded in the Sarajevo Canton, of which 642 (76.4\%) were between the ages of 0-18.

In our sample, there were $10(43.5 \%)$ male and $13(56.5 \%)$ female patients in total. In terms of age, for the descriptive statistics, we divided patients into five groups. In the 0-6 month group, there were $4(17.4 \%)$ patients; in the 6-12 month group, there were $5(21.7 \%)$ patients; in the 1-2 year group, there were $6(26.1 \%)$ patients; in the group from 2 to 5 years, there were 5 $(21.7 \%)$ patients, while in the age group of 8-14 years, there were $3(13 \%)$ patients. In comparison to the official data from the Institute for Public Health of Sarajevo Canton, $21 \%(4 / 19)$ of patients were hospitalized in the $1^{\text {st }}$ age group, $7.93 \%(5 / 63)$ in the $2^{\text {nd }}$ age group, $5.3 \%$ $(6 / 113)$ in the $3^{\text {rd }}$ age group, $1.83 \%(5 / 273)$ in the $4^{\text {th }}$ age group and $3 \%(3 / 100)$ in the $5^{\text {th }}$ age group, which are presented in Figure 1. Comorbidities were present in $9(39.1 \%)$ out of the total number of hospitalized patients and one-third of children with comorbidities had respiratory failure and required mechanical ventilation. The most common complication in patients was bronchopneumonia, present in $12(52.17 \%)$ patients. Among those hospitalized, 20 (86.95\%) were unvaccinated, while $3(13.04 \%)$ children were incompletely vaccinated, that is, they received only one dose of the MMR vaccine.

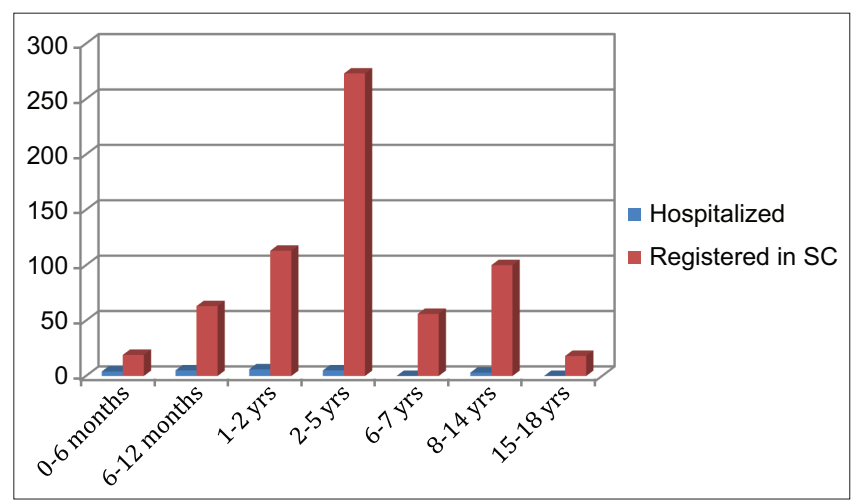

Figure 1: A comparison of hospitalized patients at the Pediatric Clinic to the official registered number of diseased patients in Sarajevo Canton

If we divide patients into two age groups: Group up to 1 year of age and group more than 1 year of age, we get data that in the first group, there were 
Table 1: Incidence of pneumonia as the most common complication in hospitalized patients, according to the age groups. Incidence in children with and without comorbidities

\begin{tabular}{|c|c|c|c|c|}
\hline \multirow[t]{3}{*}{ Age } & $0-1$ years & & \multirow{2}{*}{\multicolumn{2}{|c|}{$\begin{array}{l}1-14 \text { years } \\
14(60.87 \%)\end{array}$}} \\
\hline & \multicolumn{2}{|l|}{$9(39.13 \%)$} & & \\
\hline & Yes & No & Yes & No \\
\hline Pneumonia & $6(66.66 \%)$ & $3(33.33 \%)$ & $6(42.85 \%)$ & $8(57.14 \%)$ \\
\hline \multirow{3}{*}{ Comorbidities } & $4(44.44 \%)$ & $5(55.55 \%)$ & $5(35.71 \%)$ & $9(64.29 \%)$ \\
\hline & $\begin{array}{l}\text { Pneumonia in children with } \\
\text { comorbidities }\end{array}$ & $\begin{array}{l}\text { Pneumonia in children without } \\
\text { comorbidities }\end{array}$ & $\begin{array}{l}\text { Pneumonia in children with } \\
\text { comorbidities }\end{array}$ & $\begin{array}{l}\text { Pneumonia in children without } \\
\text { comorbidities }\end{array}$ \\
\hline & $\begin{array}{ll}\text { Yes } & \text { No } \\
3(75 \%) & 1(25 \%)\end{array}$ & $\begin{array}{ll}\text { Yes } & \text { No } \\
3(20 \%) & 2(80 \%)\end{array}$ & $\begin{array}{ll}\text { Yes } & \text { No } \\
2(40 \%) & 3(60 \%)\end{array}$ & $\begin{array}{ll}\text { Yes } & \text { No } \\
4(44.4 \%) & 5(55.5 \%)\end{array}$ \\
\hline
\end{tabular}

Table 2: Incidence of severe complications in hospitalized patients according to the age groups. Incidence in children with and without comorbidities

\begin{tabular}{|c|c|c|c|c|c|c|c|c|}
\hline \multirow[t]{3}{*}{ Age } & \multicolumn{4}{|c|}{$0-1$ years } & \multicolumn{4}{|c|}{$1-14$ years } \\
\hline & \multicolumn{4}{|c|}{$9(39.13 \%)$} & \multicolumn{4}{|c|}{$14(60.87 \%)$} \\
\hline & \multicolumn{2}{|c|}{ Yes } & \multicolumn{2}{|l|}{ No } & \multicolumn{2}{|c|}{ Yes } & \multicolumn{2}{|l|}{ No } \\
\hline Complications & \multicolumn{2}{|c|}{$4(44.44 \%)$} & \multicolumn{2}{|c|}{$5(55.55 \%)$} & \multicolumn{2}{|c|}{$3(21.42 \%)$} & \multicolumn{2}{|c|}{$11(78.57 \%)$} \\
\hline Mechanical ventilation & \multicolumn{2}{|c|}{$3(33.33 \%)$} & \multicolumn{2}{|c|}{$6(66.66 \%)$} & \multicolumn{2}{|c|}{$1(7.14 \%)$} & \multicolumn{2}{|c|}{$13(92.85 \%)$} \\
\hline Myocarditis & \multicolumn{2}{|c|}{$2(22.22 \%)$} & \multicolumn{2}{|c|}{$7(77.77 \%)$} & \multicolumn{2}{|c|}{$0(0 \%)$} & \multicolumn{2}{|c|}{$14(100 \%)$} \\
\hline CNS complications & \multicolumn{2}{|c|}{$1(11.11 \%)$} & \multicolumn{2}{|c|}{$8(88.88 \%)$} & \multicolumn{2}{|c|}{$2(14.28 \%)$} & \multicolumn{2}{|c|}{$12(85.71 \%)$} \\
\hline Exitus lethalis & \multicolumn{2}{|c|}{$2(22.22 \%)$} & \multicolumn{2}{|c|}{$7(77.77 \%)$} & \multicolumn{2}{|c|}{$0(0 \%)$} & \multicolumn{2}{|c|}{$14(100 \%)$} \\
\hline \multirow[t]{4}{*}{ Comorbidities } & \multirow{2}{*}{\multicolumn{2}{|c|}{$\begin{array}{l}\text { Complications in children } \\
\text { with comorbidities }\end{array}$}} & $5\left(55.55^{\circ}\right.$ & & $5(35.71$ & & $9(64.29 \%)$ & \\
\hline & & & \multicolumn{2}{|c|}{$\begin{array}{l}\text { Complications in children } \\
\text { without comorbidities }\end{array}$} & \multicolumn{2}{|c|}{$\begin{array}{l}\text { Complications in children with } \\
\text { comorbidities }\end{array}$} & \multicolumn{2}{|c|}{$\begin{array}{l}\text { Complications in children without } \\
\text { comorbidities }\end{array}$} \\
\hline & Yes & No & Yes & No & Yes & No & Yes & No \\
\hline & $3(75 \%)$ & $1(25 \%)$ & $1(20 \%)$ & $4(80 \%)$ & $2(40 \%)$ & $3(60 \%)$ & $1(11.1 \%)$ & $8(88.8 \%)$ \\
\hline Mechanical ventilation & $2(50 \%)$ & $1(25 \%)$ & $1(20 \%)$ & $4(80 \%)$ & $1(20 \%)$ & $3(60 \%)$ & $0(0 \%)$ & $8(88.8 \%)$ \\
\hline Myocarditis & $1(25 \%)$ & $1(25 \%)$ & $1(20 \%)$ & $4(80 \%)$ & $0(0 \%)$ & $3(60 \%)$ & $0(0 \%)$ & $8(88.8 \%)$ \\
\hline CNS complications & $1(25 \%)$ & $1(25 \%)$ & $0(0 \%)$ & $4(80 \%)$ & $1(20 \%)$ & $3(60 \%)$ & $1(11.1 \%)$ & $8(88.8 \%)$ \\
\hline Exitus lethalis & $1(25 \%)$ & $1(25 \%)$ & $1(20 \%)$ & $4(80 \%)$ & $0(0 \%)$ & $3(60 \%)$ & $0(0 \%)$ & $8(88.8 \%)$ \\
\hline
\end{tabular}

$9(39.13 \%)$, and in the second group, there were 14 $(60.86 \%)$ patients. In the first group, comorbidities were present in almost half of the patients or $4(44.44 \%)$, of whom two children required mechanical ventilation, one had myocarditis, and one died. In the first group (up to 1 year of age), there were three children with mechanical ventilation, two with myocarditis, and one with CNS complications. In the second group (1 year+), there were $5(35.71 \%)$ patients, in whom comorbidities were present, of which one child was on mechanical ventilation. In the group of children with no comorbidity but older than 1 , only one child had CNS complications such as febrile convulsions. Both lethal outcomes were in the group up to 1 year of age. All the data are represented in Tables 1 and 2.

\section{Discussion}

Out of the total number of hospitalized patients at the Pediatric Clinic, the largest percentage were infants, with the largest number of hospitalizations in March. This is an expected result, as measles usually occurs during spring and early summer, although they can be seen at any time of the year [7].

Infant age is also a risk factor for developing measles [9]. In general, antibodies obtained from the mother and through breastfeeding have a protective effect up to about 6 months, and the first dose of the MMR vaccine is given at the age of 12 months. In Bosnia and Herzegovina, measles vaccination is administered in two doses: The first dose after completing the $1^{\text {st }}$ year of life and the second dose when enrolling in the first grade of primary school, at the age of 6 . The first dose of the MMR vaccine protects children in about 93-95\% from the onset of the disease. With the second dose of the vaccine, they are protected almost $100 \%$ [10], [11]. To maintain collective immunity and prevent epidemic outbreaks, vaccination coverage needs to be over 93\% [12].

Measles can occur at any age, but they most commonly occur in children under the age of 5 [1], [13]. Boys and girls are equally affected by measles [14].

Comorbidity is also a risk factor for the development of a more severe clinical picture in measles patients. Of the total nine patients with comorbidities, three developed respiratory failure. Most patients with respiratory failure and comorbidities were in infant age. Furthermore, both deaths were at this age.

Complications of measles occur in 10-40\% of cases. They are more common and more serious in smaller children [15], and bronchopneumonia may be the most common complication in patients [16]. Our research results are in line with the literature data, citing bronchopneumonia as the most common complication, present in as many as $52.17 \%$ of patients. Both patients who died $(8.69 \%)$ had bronchopneumonia and myocarditis as complications. Neurological complications include febrile seizures, primary measles encephalitis, acute post-infectious encephalomyelitis, measles inclusion body encephalitis, and subacute sclerosing panencephalitis [17]. In our patients, there were no serious acute neurological complications. CNS complications in the form of febrile seizures were reported by one patient $(4.35 \%)$ in the group of children over one year of age.

Myocarditis can also occur as a complication of measles [18]. Both of our patients who died (8.69\%) had 
bronchopneumonia and myocarditis, and consequently respiratory failure, as complications.

Although the measles vaccine has been used around the world for over 50 years and has proven to be very safe and effective, according to our study results, the highest percentage of hospitalized patients had not received a single dose of the MMR vaccine. The strong anti-vaccine movement as well as the association of the MMR vaccine with the development of autism in children have also had a strong impact in our area. $A$ meta-analysis based on the evidence of five cohort studies ( $n=12,56,407)$ and five case-control studies ( $n=9920$ ) found no evidence of an association between MMR vaccination and subsequent development of autism or autism spectrum disorders [19]. For now, however, there is no clear answer as to when and how to respond. The views of the WHO European Office (2014) and the United States National Center for Immunization on this issue are quite consistent: (1) To respect the legitimate concerns of parents; (2) always truthfully present the benefits and risks of vaccines and involve parents in the decision making; (3) complete the facts with examples from life; (4) use children to educate parents; (5) adapt messages to the needs of the target groups, using different strategies; and (6) make journalists aware of the overwhelming scientific evidence in support of vaccination. Furthermore, numerous studies in the world that has addressed this issue have found no correlation between the MMR vaccine and the subsequent development of autism or the autism spectrum disorder. Consequently, the measles epidemic in our country should only be a reminder of the failure to vaccinate children. To prevent the far-reaching consequences of non-vaccination, it is necessary to take certain measures and activities in our country. Activities should primarily aim at raising public awareness of the importance of vaccination and, on the other hand, should encourage pediatricians and healthcare professionals, especially at the primary care level, to contribute to raising parents' awareness of the importance of vaccination. Only the responsible behavior of parents, health professionals, and society as a whole can prevent the far-reaching consequences of non-vaccination.

\section{Conclusion}

Measles can best be prevented by vaccination. Continuous education should be conducted in order to advance the knowledge of all factors involved in the immunization system. Through knowledge on the importance of immunization, especially at the level of primary health care, public awareness can be raised. Infants, as the most vulnerable part of the population, are particularly at risk if collective immunity is impaired.
Even deaths at this age are not uncommon, especially when it comes to associated comorbidities, where the youngest patients very often have complications and develop respiratory failure. Every child's life is an irreparable loss because it is a vaccine-preventable disease.

\section{Author's Contribution}

Each author gave substantial contribution to the conception or design of the work and in the acquisition, analysis, and interpretation of data for the work. Each author had a role in drafting the work and revising it critically for important intellectual content. Each author gave final approval of the version to be published and they agree to be accountable for all aspects of the work in ensuring that questions related to the accuracy or integrity of any part of the work are appropriately investigated and resolved.

\section{References}

1. Paules $\mathrm{Cl}$, Marston HD, Fauci AS. Measles in 2019 going backward. N Engl J Med. 2019;380(23):2185-7.

PMid:30995368

2. World Health Organization. Global Measles and Rubella Update. Geneva: World Health Organization; 2018. Available from: https://www.who.int/immunization/monitoring_surveillance/ burden/vpd/surveillance type/active/Global MR Update November_2018.pdf?Ua=1. [Last accessed on 2019 Jan 30].

3. Rota PA, Moss WJ, Takeda M, de Swart RL, Thompson KM, Goodson JL. Measles. Nat Rev Dis Primers. 2016;2:16049. PMid:27411684

4. Moss WJ. Measles. Lancet. 2017;390(10111):2490502. PMid:28673424

5. Angelo KM, Gastanaduy PA, Walker AT, Patel M, Reef S, Lee CV, et al. Spread of measles in Europe and implications for US travelers. Pediatrics. 2019;144:414.

PMid:31209161

6. Centers for Disease Control and Prevention. Epidemiology and Prevention of Vaccine Preventable Diseases. The Pink Book: Course Tethbook. Atlanta, Georgia: Centers for Disease Control and Prevention; 2015.

7. O'Donnell S, Davies F, Vardhan M, Nee P. Could this be measles? Emerg Med J. 2019;36(5):310-4.

8. Schoini $P$, Karampitsakos T, Avdikou M, Athanasopoulou A Tsoukalas G, Tzouvelekis A. Measles pneumonitis. Adv Respir Med. 2019;87(1):63-7.

PMid:30830960

9. Bentley J, Rouse J, Pinfield J. Measles: Pathology, management and public health issues. Nurs Stand. 2014;28(38):51-8.

PMid:24844521

10. Lindberg C, Lanzi M, Lindberg K. Measles: Still a significant health threat. MCN Am J Matern Child Nurs. 2015;40(5):298305. 
PMid:26110575

11. Bester JC. Measles and measles vaccination: A review. JAMA Pediatr. 2016;170(12):1209-15.

PMid:27695849

12. Kondamudi NP, Whitten RA. Measles. Treasure Island FL: StatPearls; 2019.

13. World Health Organization. Global Measles and Rubella Strategic Plan 2012-2020. Available from: https://www. who.int/immunization/monitoring_surveillance/burden/vpd/ surveillance_type/active/Global_MR_Update_November_2018. pdf?ua=1. [Last accessed on 2019 Jul 30].

14. Gans H, Maldonado YA. Measles: Epidemiology and Transmission. Available from: https://www.uptodate.com/ contents/measles-epidemiology-and-transmission.

[Last accessed on 2019 Aug 11].

15. Kumar D, Sabella C. Measles: Back again. Cleve Clin J Med.
2016;83(5):340-4.

PMid:27168508

16. Dardis MR. A review of measles. J Sch Nurs. 2012;28(1):9-12. PMid:22140138

17. Leung $\mathrm{AK}$, Hon KL, Leong KF, Sergi CM. Measles: A disease often forgotten but not gone. Hong Kong Med J. 2018;24(5):512-20.

PMid:30245481

18. Blauwet LA, Cooper LT. Myocarditis. Prog Cardiovasc Dis. 2010;52(4):274-88.

PMid:20109598

19. Taylor LE, Swerdfeger AL, Eslick GD. Vaccines are not associated with autism: An evidence-based meta-analysis of case-control and cohort studies. Vaccine. 2014;32(29):36239.

PMid:24814559 